\title{
Brain hypoperfusion in adolescents dependent of multiple drugs
}

\author{
Elba Cristina Sá de Camargo Etchebehere1, \\ Felipe Martins Oliveira', Bárbara Juarez Amorim?', \\ Saulo Monte Serrat'², Edwaldo Eduardo Camargo'
}

\begin{abstract}
Brain SPECT imaging (BSI) with statistical parametric mapping (SPM) offers a clear and accurate vision of perfusion changes. Objective: To study brain perfusion abnormalities in adolescents' dependent of multiple drugs. Method: Sixteen male patients (15.1 12.1 years)

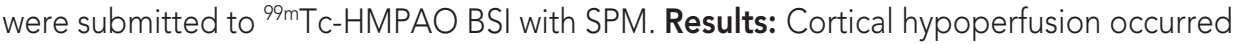
in $7 / 16$ patients (44\%). There was a significant inverse correlation between the number of hypoperfused regions and the patient's age $(p=-0.6737 ; p=0.004)$ and with the age when the drug dependence began $(p=-0.5616 ; p=0.023$ ). There was also a tendency towards an inverse correlation between regions of hypoperfusion and the duration of the drug dependence. Conclusion: BSI with SPM can help detect hypoperfusion in adolescents dependent on multiple drugs. The younger the patients, the more regions of hypoperfusion are noted. Probably, the neuronal plasticity has an important role in this phenomenon because the highest neural activity occurs in childhood.

Key words: computed tomography, emission-computed, single-photon, substance-related disorders, drug abuse, drug addiction, substance abuse, substance dependence drug abuse.
\end{abstract}

\section{Hipoperfusão cerebral em adolescentes dependentes de múltiplas drogas}

\section{RESUMO}

SPECT cerebral (SC) com statistical parametric mapping (SPM) oferece uma visão clara e acurada de alterações perfusionais. Objetivo: Avaliar anormalidades perfusionais cerebrais em adolescentes usuários de múltiplas drogas. Método: Dezesseis pacientes masculinos $(15,1 \pm 2,1$ anos) foram submetidos a SC com SPM utilizando-se HMPAO--99m Tc. Resultados: Hipoperfusão cortical ocorreu em $7 / 16$ pacientes (44\%). Houve uma significativa correlação inversa entre o número de áreas hipoperfundidas e a idade dos pacientes ( $p=-0,6737$; $p=0,004)$ e com a idade quando iniciaram $o$ abuso das drogas $(p=-0,5616 ; p=0,023)$. Também houve uma tendência para uma correlação inversa entre as áreas de hipoperfusão e a duração do abuso de drogas. Conclusão: SC com SPM pode auxiliar na detecção de hipoperfusão cortical em adolescentes dependentes de múltiplas drogas. Quanto menor a idade, mais áreas de hipoperfusão são identificadas. Provavelmente a plasticidade neuronal tem importante papel neste fenômeno, pois a maior atividade neuronal ocorre na infância. Palavras-chave: tomografia computadorizada de emissão de fóton único, transtornos relacionados ao uso de substâncias, abuso de drogas, abuso de substâncias, drogadicção, dependência por abuso de drogas.

\section{Correspondence}

Elba C.S.C. Etchebehere

Serviço de Medicina Nuclear do Hospital de Clínicas da UNICAMP

Av. Zeferino Vaz S/N - Cx Postal: 6142 13081-970 Campinas SP - Brasil E-mail:elba@mn-d.com

Received 6 July 2009

Received in final form 23 October 2009 Accepted 9 November 2009
Drugs such as tobacco, alcohol, marijuana, solvents, cocaine and crack are a matter of concern by the World Health Organization due to the great number of deaths. Some students and homeless adolescents in Brazil are frequent dependent of multiple drugs. Illegal drug dependence has required currently more attention of

'Division of Nuclear Medicine, Department of Radiology, School of Medical Sciences, Campinas State University (UNICAMP), Campinas SP, Brazil; ${ }^{2 B r a z i l i a n ~ F e d e r a t i o n ~ o f ~ T h e r a p e u t i c ~ C o m m u n i t y ~(F E A C), ~ C a m p i n a s ~ S P, ~ B r a z i l . ~}$ 
the health care professionals since it has become a matter of public health. Consistent health policies are necessary in order to reduce the chronic drug dependence levels. In this process, the use of tests to detect cerebral changes in drug dependents are, therefore, priceless tools for dealing with this public health issue. The investigation of these changes in the central nervous system has been facilitated by the use of neuroimaging. PET, SPECT and MRI provide different information of the human brain.

Tobacco affects mainly the respiratory and cardiovascular systems ${ }^{1}$, however, while chronic alcohol abuse affects the digestive and neurologic systems. Neuroimaging studies in alcohol abusers have shown that structural and functional damages mainly in the frontal lobes ${ }^{2-4}$, hippocampus and even in the cerebellar cortex with acute alcohol intoxication ${ }^{5}$.

Cannabis sativa (marijuana) abusers display cognitive impairment and respiratory diseases and neuroimaging studies have demonstrated hypoperfusion in the temporal lobes and severe abnormalities among those that begin abusing the drug earlier ${ }^{6-7}$.

Chronic dependence of solvents in the central nervous system causes peripheral neuropathy, cerebellar dysfunction and dementia. MRI and CT studies have shown diffuse cerebral and cerebellar atrophy, including the hippocampus and corpus callosum ${ }^{8-10}$.

Crack is the volatile product of cocaine that has shown to be more powerful than cocaine. Crack has a strong, however short, effect thus causing an increase in the frequency of inhalation of the drug ${ }^{11}$. Crack affects the cardiovascular, respiratory and neurologic systems. The neurovascular effects of cocaine and crack abuse can lead to carotid, vertebral and basillar artery infarcts and, therefore, with great potential to induce many cerebral cortical damages. Hypoperfusion and glucose hypometabolism have been demonstrated in the frontal, temporal and parietal cortices ${ }^{12,13}$. The price of crack being low increases the number of abusers mainly among the poor population ${ }^{14}$.

Brain SPECT imaging (BSI) has the ability to detect changes early on in the course of disease, before structural changes are noted in anatomical imaging modalities as MRI. There are few studies which describe brain SPECT perfusion changes in adolescent drug dependents ${ }^{15,16}$. Statistical parametric mapping (SPM) is a statistical tool which is operator-independent and has been used in BSI, mainly in epilepsy ${ }^{17}$. The SPM offers a clear vision of perfusion changes.

The objective of this investigation is to study brain perfusion abnormalities in adolescents dependent of multiple drugs using statistical parametric mapping.

\section{METHOD}

The patient group was composed of 16 male adoles- cents (11 to 18 years, mean $15.1 \pm 2.1$ years). All patients were dependent of multiple drugs enrolled in a recovery program at the Brazilian Federation of Therapeutic Community (FEAC). Mean age at the beginning of drug dependence was $11.1 \pm 2.12$ years (from 4 to 16 years). The duration of the drug dependence was $2.8 \pm 1.91$ years. They had used the following drugs: crack, cocaine, alcohol, marijuana and solvents. For the purpose of this study, all patients enrolled had to have been in a drug-free condition for at least 6 months. Information regarding the severity of drug dependence and relation of the respective drugs used by each individual was not possible because these were homeless, illiterate street adolescents.

Since these patients were considered orphans, the guardian for these patients was FEAC, determined by the County Court Jurisdiction of Children and Adolescents of Campinas. Informed consent for performing these studies was obtained by FEAC and by the court of law as well.

The inclusion criteria consisted of patients dependent of multiple drugs enrolled in a recovery program in a drug-free condition for at least 6 months.

The exclusion criteria consisted of patients with any neurological disorder that might alter brain perfusion and cause false positive results in BSI, such as neuropsychiatric disorders, mental retardation, epilepsy, tumors, malformations etc.

The control group was composed of 35 normal volunteers, 30 males and 5 females, mean age 14 years \pm 6.6 years (6 to 23 years). The Ethical Committee had approved the use of brain SPECT in those normal volunteers.

\section{Brain SPECT imaging (BSI)}

All the patients were in a free of drug dependence condition for at least 6 months when the BSIs were acquired.

BSI was performed using hexamethylpropilene-amine oxime (HMPAO), labeled with technetium-99m.

Patients and control subjects were required to remain resting in a dark quiet room for 10 minutes. While at rest, they received an intravenous injection of $7.9 \mathrm{MBq} /$ $\mathrm{kg}(0.43 \mathrm{mCi} / \mathrm{kg})$ of ${ }^{99 \mathrm{~m}} \mathrm{Tc}-\mathrm{HMPAO}$ and were required to rest for 10 additional minutes. Studies were acquired at least 30 minutes after injection.

Sixty images were acquired at $6^{\circ}$ intervals for a total of $360^{\circ}$ on a GE HR-APEX SP6 1 HEAD scintillation camera equipped with a fan beam collimator. Images were acquired on a $64 \times 64$ matrix and normalized using a Metz filter. After reconstruction with attenuation correction, the images were displayed in the transaxial, coronal and sagittal planes.

\section{Statistical parametric napping (SPM) analysis}

Reconstructed transaxial datasets were transformed into ANALYZE format (Fig) and corrected for the orthog- 


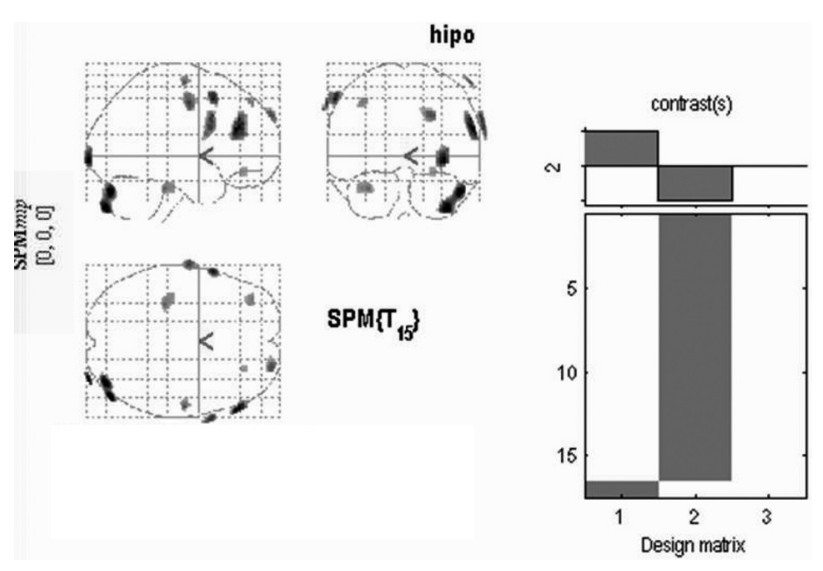

Figure. ANALYZE format of a reconstructed transaxial dataset.

onal plane of acquisition using MRIcro software (Chris Rorden, http://www.mricro.com). Voxel based analysis was performed using SPM2 (Wellcome Department of Cognitive Neurology, http://www.fil.ion.ucl.ac.uk). To compare between groups, individual brain size variability was previously corrected by spatially normalizing each image to a template defined in the atlas of Talairach and Tournoux. This process involves the estimation of the optimum 12 parameter affine transformation (linear normalization). The normalized images were smoothed by convolution with an Isotropic Gaussian Kernel (FWHM) of $6 \mathrm{~mm}$. The ${ }^{99 \mathrm{~m}} \mathrm{Tc}-\mathrm{HMPAO}$ uptake was standardized to the mean global uptake using a proportional scale.

Comparison between groups was performed by using the two sample t-test. The SPM results were divided in 7 brain regions: frontal, temporal, parietal, occipital, cerebellar, thalami and basal ganglia. The regions with significant differences were determined at the cluster level (a group of variable number of voxels). The results of the analysis were displayed as a statistic parametric map of tstatistic $\left(\mathrm{SPM}_{(\mathrm{t})}\right)$, and the $\mathrm{SPM}_{\mathrm{t}}$ was corrected to the normal distribution $\left(\operatorname{SPM}_{(\mathrm{z})}\right)$. We used the $\mathrm{p}(\mathrm{FDR}$ - false discovered rate) which minimizes false positive results. The results were displayed in three orthogonal planes. The regions where a significant difference was seen were fused in a standardized MRI from SPM for better anatomical localization.

\section{Statistical analysis}

BSI perfusion findings from each patient were compared to the control group. It was not the scope of this study to assemble all patients together for a SPM group comparison versus healthy control adolescents. These results were not correlated with anatomical changes, such as presence of brain atrophy, since only a few of patients had been submitted to brain CT and none to MRI.

The Mann-Whitney test was applied in the visual analyses to compare the duration of the drug dependence with the number of hypoperfused regions. The Spearman's correlation coefficient was applied to compare the duration of the drug dependence with each region of cortical hypoperfusion. Differences were considered significant at a level of $5 \%$.

In the SPM analysis, areas of cortical hipoperfusion were correlated with patient's age when BSI was performed, at the beginning of drug dependence and with the duration of the drug dependence. The Spearman's correlation coefficient was applied for these tests and differences were considered significant at a level of $5 \%$. The non-parametric Wilcoxon's test was applied to the SPM analysis.

\section{Ethical aspects}

The presented research was approved by the Ethical Committee of the School of Medical Sciences, Campinas State University (UNICAMP) and has been performed in accordance with 1964 Declaration of Helsinki. The Ethical Committee had approved the use of BSI in the normal volunteers.

\section{RESULTS}

\section{SPM analysis}

Cortical hypoperfusion occurred in $7 / 16$ patients (44\%). The other 9 patients (56\%) did not have any area of hypoperfusion (Table 1).

Hypoperfusion in only one cortical region occurred in 3/16 patients (19\%), in 4 regions in 2/16 (13\%), in 5 regions only in one patient (6\%) and one patient (6\%) had hypoperfusion in all the seven regions analyzed (Table 2).

There was a significant inverse correlation between the number of hypoperfused regions and the patient's age when BSI was performed (Spearman's correlation coefficient $=-0.6737 ; \mathrm{p}=0.004)$. Younger patients presented significant hypoperfusion in the parietal lobes $(\mathrm{p}=0.05)$, occipital lobes ( $\mathrm{p}=0.01)$ and cerebellum $(\mathrm{p}=0.02)$.

There was also a significant inverse correlation between the number of hypoperfused regions and the patient's age at the beginning of the drug abuse (Spearman's correlation coefficient $=-0.5616 ; \mathrm{p}=0.023$ ), thus the younger the patient, the more frequent the hypoperfused regions. Younger patients presented significant hypoperfusion in the temporal lobes $(\mathrm{p}=0.04)$ and occipital lobes $(\mathrm{p}=0.03)$.

There was a tendency towards an inverse correlation between regions of hypoperfusion and the duration of drug dependence; the longer the time of drug dependence the greater the tendency to find more hypoperfused regions. However, this finding was not statistically significant.

Thalami and basal ganglia hypoperfusion were not analyzed since these alterations occurred in only one patient. 
Table 1. Hypoperfused regions detected on brain SPECT imaging by SPM.

\begin{tabular}{|c|c|c|c|c|c|c|c|c|c|c|c|}
\hline \multirow[b]{2}{*}{ Pt. } & \multirow{2}{*}{$\begin{array}{c}\text { Pt. age when BSI } \\
\text { was acquired (years) }\end{array}$} & \multirow{2}{*}{$\begin{array}{c}\text { Pt. age when drug } \\
\text { dependence began (years) }\end{array}$} & \multirow{2}{*}{$\begin{array}{l}\text { Duration of drug } \\
\text { depence (years) }\end{array}$} & \multicolumn{7}{|c|}{ SPM } & \multirow[b]{2}{*}{ Drugs used } \\
\hline & & & & $\mathrm{F}$ & $T$ & $\mathrm{P}$ & 0 & $\mathrm{C}$ & Th & BG & \\
\hline 1 & 12 & 9 & 1 & & + & + & + & + & & & $A, C R, M, S$ \\
\hline 2 & 15 & 13 & 2 & & & & & + & & & $A, C, C R, M, S$ \\
\hline 3 & 18 & 13 & 5 & & & & & & & & $C, C R, M, S$ \\
\hline 4 & 16 & 10 & 5.5 & & & & & & & & $A, C R, M, S$ \\
\hline 5 & 14 & 9 & 5 & & & & & & & & $C, C R, M, S$ \\
\hline 6 & 15 & 12 & 0.5 & + & + & + & + & + & & & $A, C R, M, S$ \\
\hline 7 & 13 & 8 & 2 & + & + & & + & + & & & $A, C R, M$ \\
\hline 8 & 17 & 11 & 6 & & & & & & & & $C, C R, M$ \\
\hline 9 & 17 & 12 & 5 & & + & & & & & & $A, C, C R, M, S$ \\
\hline 10 & 16 & 13 & 1.5 & & & & & & & & $C R$ \\
\hline 11 & 11 & 7 & 2 & + & + & + & + & + & + & + & $A, C R, M, S$ \\
\hline 12 & 15 & 14 & 0.5 & & & & & & & & $A, C R, S$ \\
\hline 13 & 14 & 9 & 3 & & & & & & & & $C R, M, S$ \\
\hline 14 & 18 & 13 & 2 & & & & & & & & $A, C, C R, M, S$ \\
\hline 15 & 14 & 12 & 1 & & & & & & & & $C, C R, M, S$ \\
\hline 16 & 17 & 13 & 4 & + & & & & & & & $C R, M, N$ \\
\hline
\end{tabular}

Pt: patient; F: frontal; T: temporal; P: parietal; O: occipital; C: cerebellum; Th: thalami; BG: basal ganglia; +: presence of hypoperfusion; A: alcohol; C: cocaine; CR: crack; M: marijuana; N: nicotine; S: solvents.

Table 2. Correlations between brain hypoperfusion regions from SPM analysis and the patient's age when BSI was performed; at the beginning of drug dependence; with the duration of drug dependence.

\begin{tabular}{lccc}
\hline Cerebral regions of hypoperfusion & $\begin{array}{c}\text { Age when BSI was } \\
\text { performed ( } p \text {-value) }\end{array}$ & $\begin{array}{c}\text { Age at beginning of drug } \\
\text { dependence ( } p \text {-value) }\end{array}$ & $\begin{array}{c}\text { Duration of drug } \\
\text { dependence ( } p \text {-value) }\end{array}$ \\
\hline Frontal & $0.27^{*}$ & $0.27^{*}$ & $0.43^{*}$ \\
Temporal & $0.08^{*}$ & $0.04^{*}$ & $0.28^{*}$ \\
Parietal & $0.05^{*}$ & $0.11^{*}$ & $0.08^{*}$ \\
Occipital & $0.01^{*}$ & $0.03^{*}$ & $0.09^{*}$ \\
Cerebellum & $0.02^{*}$ & $0.12^{*}$ & $0.09^{*}$ \\
Number of hypoperfusion regions & $-0.6737^{*}$ & $-0.5616^{*}$ & $-0.4123^{* *}$ \\
\end{tabular}

*Wilcoxon's test; **Spearman coefficient.

In the present study a correlation between the numbers of hypoperfused regions with the abstinence period was also analyzed in order to evaluate if hypoperfusion defects were reversible after a long abstinence period. There were more perfusion defects in patients that had been drug free for at least two years ( 4 patients), while those patients that were abstinent for 6 months to 18 months (9 patients) had only one perfusion defect at the most. There was one patient with a 3-year abstinence period. This patient had only one perfusion defect.

It must be noted that in the present study differences related to the type of drug addiction was not observed since all patients used at one time or another all drugs cited.

\section{DISCUSSION}

In the present study, brain hypoperfusion was noted in these patients, which confirms findings of several studies involving drug dependence and perfusion abnormalities. BSI perfusion findings from each patient were compared to the control group. It was not the scope of this study to assemble all patients together for a SPM group comparison versus healthy control adolescents, as is performed in the majority of the published data. We preferred a more practical approach, as our prior published data ${ }^{17}$. It must be noted that in the present study, the differences related to the type of drug addiction was not observed since all patients used at one time or another all drugs cited.

Okada et al. studied solvent dependents and described 
BSI hypoperfusion in the pre-frontal cortex of these patients and suggested that the amotivational syndrome that occurs in these patients may be explained by these findings. The exact mechanism by which brain hypoperfusion occurs in solvent dependents is not known; a possible explanation is that solvents can directly affect the blood vessels causing spasms and therefore obstruction. Another hypothesis could be a decrease in cellular activity or even death $^{18}$. In long-term inhalant dependents of toluene, acetone, benzene and derivatives Kücük et al. noted in BSI marked hypoperfusion in the temporal and parietooccipital regions ${ }^{19}$. In contrast, Volkow et al., noted prefrontal cortex hypoperfusion in chronic dependents of inhalants in BSI which correlated with the severity of the apathy that these patients present ${ }^{20}$.

Cannabis young adult users have been submitted to FDG $-{ }^{18} \mathrm{~F}$ PET imaging with SPM99 analysis and have shown lower glucose metabolism in the right orbitofrontal cortex, putamen bilaterally, and precuneus regions ${ }^{21}$.

The effects of cocaine in brain perfusion are better known. Nicastri et al. showed hypoperfusion in the temporal lobes of cocaine dependents. The authors used ${ }^{99 \mathrm{~m}}$ Tc-ECD and also observed, in isolated patients, perfusion irregularities in the pre-frontal cortex ${ }^{22}$. Hypoperfusion defects in cocaine dependents are caused by vascular occlusion secondary to platelet activation and formation of microthrombi. Silverman et al. demonstrated that cocaine causes prolonged vasoconstriction in some vessels ${ }^{23}$. Ernst et al. studied BSI (coregistreted with MRI) in cocaine dependents and showed hyperperfusion in the globus pallidus and hypoperfusion in the putamem and temporal lobes ${ }^{24}$.

Dependents of crack were studied by Weber et al. The authors noted on BSI with ${ }^{123}$ I-IMP that 16/21 asymptomatic crack dependents presented foci of reduced activity mainly in the frontal and parieto-occipital cortex or marked perfusion irregularities throughout the entire cerebral cortex ${ }^{25}$. These findings are in agreement with ours because crack was the only drug used by all patients and we also found hypoperfusion in the same regions. However, in their study, no correlation was noted between the incidence and severity of SPECT perfusion abnormalities with the frequency, amount or length of time of crack use. In our study, a significant correlation was observed between perfusion alterations (temporal, parietal, occipital and cerebellar hypoperfusion) and the patient's age when BSI was performed and/or at the beginning of the drug dependents.

Decreased perfusion in the anterior cingulate/frontal regions among cocaine-dependent men have been shown by Tucker et $\mathrm{al}^{26}$. The authors performed ${ }^{99 \mathrm{~m}} \mathrm{Tc}$ HMPAO SPECT SPM and compared the findings with controls and cocaine-dependent women. The perfusion defects differed from in cocaine-dependent women (posterior cingulated defect). Therefore, the authors suggest that different neural mechanisms underlie relapse in men and women. This may be the same for our study group, composed of only male patients.

Cerebellar hypoperfusion, which was also detected in our study, had a significant inverse correlation with the age of the patient when BSI was performed. There are two possible explanations for this finding. This phenomenon may be secondary to a diaschisis caused by cortical hemisphere hypoperfusion. Chugani et al. reported a crossed cerebellar diaschisis in hemispherectomized adolescents which is reversible ${ }^{27}$. Another explanation for this perfusion defect could be a direct damage from the drug, such as in other brain regions.

There is no consensus regarding the reversibility of perfusion alterations. Holman et al. described an improvement in BSI perfusion in cocaine dependents after abstinence and specific therapy ${ }^{28}$. They studied 10 patients after 7 to 8 days and 17 to 29 days after abstinence and buprenorphine and noted improvement of the hypoperfusion by a mean of $11 \%$ and $24 \%$, respectively. Some lesions secondary to vasospasm and endothelial dysfunction could explain persistent cerebral hypoperfusion even under abstinence, as showed by González et al. ${ }^{29}$ in a study involving 60 patients after 28 days without drug dependence. Atrophic lesions detected by structural neuroimaging in cocaine dependents could be associated with irreversible loss of brain tissue while funcional neuroimaging could detect potentially reversible brain alterations.

All patients enrolled had to have been in a drug-free condition for at least 6 months. Information regarding the severity of drug dependence and relation of the respective drugs used by each individual was not possible because these were homeless, illiterate street adolescents. Perhaps the six month abstinence period may not be enough to reverse the perfusion alterations.

In the present study a correlation between the numbers of hypoperfused regions with the abstinence period was also analyzed in order to evaluate if hypoperfusion defects were reversible after a long abstinence period. To our surprise there were more perfusion defects in patients that had been drug free for at least two years than those abstinent for 6 months to 18 months (9 patients) which would suggest that these defects may not be reversible. On the other hand, the one patient with a 3-year abstinence period had only one perfusion defect. Therefore, a long-term follow-up of these patients is needed to evaluate actually when brain damage installs and at what age. The youngest patient evaluated in our study began drug abuse at the age of 7 and had an abstinence period of 2 years. This patient had the greatest number of perfusion 
defects on BSI. Possibly the age when drug abuse began is the most important aspect in determining perfusion defects in the long run, more so than the abstinence period.

To our knowledge, there is only one study with BSI using SPM in cocaine and alcohol dependents ${ }^{30}$. The authors showed more areas of hypoperfusion in alcohol and cocaine dependents than in cocaine dependents only. They found hypoperfusion mainly in the occipital, temporal and cerebellar regions.

Some studies suggest a higher brain functional reorganization in adolescents that have had unilateral brain lesions at an early age when compared to those that have had brain lesion later in life ${ }^{27}$. This phenomenon may justify the inverse correlation found between hypoperfusion and the patient's age when BSI was performed as well as with the age when the drug abuse began. Thus, perfusion alterations may be age-related, so that it is important to know the metabolic brain characteristics and neural plasticity which determines reorganization at of the adolescent's brain.

Glucose brain metabolism displays a typical curve with an ascending portion from the birth up to 4 years of age and reaches a plateau by 10 years of age. Only after 10 years of age does the glucose metabolism consumption gradually decrease to levels similar to adults between 16 and 18 years. Assuming that glucose metabolism is related to the synapses, the ascending portion of the curve represents a period of synaptic proliferation, while the plateau represents a great number of synapses and their connections $^{31}$. Changes in brain metabolism observed with glucose reflect in perfusion changes as well ${ }^{32,33}$ thus both PET and SPECT may be used to evaluate alterations due to drug dependence. Most patients from our study began drug dependence in the period of the plateau curve, when glucose metabolism was the highest. This could explain the association found between regions of hypoperfusion (temporal, occipital and number of hypoperfused regions) and the patient's age at the beginning of the drug abuse. Adolescents who began their drug abuse earlier had more hypoperfusion in these regions. Probably, after 10 years, when the glucose metabolism starts to decrease, the probability of causing damage in the brain decreases.

Parietal, occipital and cerebellar hypoperfusion had a significant correlation with the patient's age when the BSI was performed. The younger the patient, the more areas of hypoperfusion appeared. There was a tendency towards an inverse correlation between the number of regions hypoperfused and the duration of drug dependence; thus the longer the time of drug dependence the greater the tendency to find more hypoperfused regions. However, this finding was not statistically significant. Since it was not possible to estimate the amount of drug used by each patient and the number of patients studied was small, more patients are needed to confirm this finding.

The correlation of the neuronal alterations and the history of drug dependence noted in our study is similar to that reported by Buchert et al. ${ }^{34}$ on 3,4-methylenedioxymethamphetamine, popularly known as 'ecstasy' dependence. These authors performed FDG ${ }^{18} \mathrm{~F}$ PET images in 93 ecstasy users and 27 controls. The FDG uptake was reduced within the striatum and amygdala of ecstasy users when compared to controls especially those patients that began consuming before 18 years of age. These findings are similar to our own with patients addicted to multiple drugs.

The limitations of this study were the relatively small number of patients studied and the fact that all adolescents were addicted to multiple drugs. Thus it was not possible to match the perfusion defects with a specific drug, reducing the specificity of the perfusion defects to a specific drug.

This is the first study to apply SPM to BSI in adolescents addicted to multiple drugs.

BSI can help to detect perfusion abnormalities in adolescents addicted to multiple drugs. The younger the patients, the more regions of hypoperfusion are noted. Probably, neuronal plasticity has an important role in this phenomenon because the highest neural activation occurs in childhood. However, the question of reversibility of the defects remains unanswered.

\section{REFERENCES}

1. Roemer R. Legislative action to combat the world tobacco epidemic. World Health Organization 1993:297.

2. Nicolas JM, Catafau AM, Estruch R, et al. Regional blood flow-SPECT in chronic alcoholism: relation to neuropsychologxical testing. J Nucl Med 1993;34:14521459.

3. Sanson Y, Baron JC, Feline A, Bories J, Crouzel C. Local cerebral glucose utilization in chronic alcoholics: a positron tomographic study. J Neurol Neurosurg Psychiatry 1986;49:1165-1170.

4. Besson JAO. Structural and functional brain imaging in alcoholism, and drug misuse. Curr Opin Psychiatry 1993;6:403-410.

5. Volkow ND, Mullani N, Gould L, et al. Effects of acute alcohol intoxication on cerebral blood flow measured with PET. Psychiatry Res 1988;24:201-209.

6. Amen DG, Waugh M. High resolution brain SPECT imaging of marijuana smokers with AD/HD. J Psych Drugs 1998;30:209-214.

7. Wilson W, Mathew R, Turkington T, Hawk T, Coleman RE, Provenzale J. Brain morphological changes and early marijuana use: a magnetic resonance and positron emission tomography study. J Addict Dis 2000;19:1-22.

8. Flanagan RJ, Ives RJ. Volatile substance abuse. Bull Narcotics 1994:46:49-78.

9. Sudbury PR, Ghodse AH. Solvent misuse. Curr Opin Psychiatry 1990;3:388-392.

10. Yamanouchi N, Okada S, Kodama K, Sato T. Central nervous system impairment caused by chronic solvent abuse: a review of Japanese studies on the clinical and neuroimaging aspects. Addic Biol 1998;3:15-27.

11. Seibel SD. Cocaína (e Crack) In: Seibel SD, Toscano Jr A (Eds). Dependência de drogas. São Paulo: Atheneu, 2001:121-127.

12. Chang L, Ernst T, Strickland T, Mehringer M. Gender effects on persistent cerebral metabolite changes in the frontal lobes of abstinent cocaine users. Am J Psychiatry 1999;156:716-722.

13. Silveira DX, Fernandes M, Barbieri A, Labigalini E, Silveira ED. Fatores associados a perfusão cerebral anormal em dependentes de cocaína. Rev Bras Psiquiatr 2001;23:9-14

14. Dunn J, Ferri CP. The price of crack in São Paulo, Brazil. Addiction 1998; 93:287-288. 
15. Browndyke JN, Tucker KA, Woods SP, et al. Examining the effect of cerebral perfusion abnormality magnitude on cognitive performance in recently abstinent chronic cocaine abusers. J Neuroimaging 2004;163:162-169.

16. González JP, Vega TM, Soto PA, Espinoza PG, Garib FC, Padilla PP. Comportamiento de la perfusión cerebral con tomografía SPECT-99mTc etilencisteína dímero (ECD) en dependientes a alcohol y cocaína durante abstinencia. Rev Esp Med Nucl 2002;411:410-416.

17. Amorim BJ, Etchebehere ECSC, Camargo EE, et al. Statistical voxel-wise analysis of ictal SPECT reveals pattern of abnormal perfusion in patients with temporal lobe epilepsy. Arq Neuropsiquiatr 2005;63:977-983.

18. Okada S, Yamanouchi N, Kodama K, et al. Regional cerebral blood flow abnormalities in chronic solvent abusers. Psychiatry Clin Neurosci 1999;53:351-356.

19. Kucuk NO, Kilic EO, Ibis E, et al. Brain SPECT findings in long-term inhalant abuse. Nucl Med Communications 2000;21:769-773.

20. Volkow ND, Fowler JS, Wang GJ. Positron emission tomography and singlephoton emission computed tomography in substance abuse research. Sem Nucl Med 2003;2:114-128.

21. Sevy S, Smith GS, Ma Y, et al. Cerebral glucose metabolism and D2/D3 receptor availability in young adults with cannabis dependence measured with positron emission tomography. Psychopharmacology 2008;197:549-556.

22. Nicastri S, Buchpiguel CA, Andrade AG. Anormalidades de fluxo sangüíneo cerebral em indivíduos dependentes de cocaína. Rev Bras Psiquiatr 2000;22:42-50.

23. Silverman DG, Kosten TR, Jatlow PI, et al. Decreased digital flow persists after abatement of cocaine-induced hemodynamic stimulation. Anesth Analg 1997;84:46-50.

24. Ernst T, Chang L, Oropilla G, Gustavson A, Speck O. Cerebral perfusion ab- normalities in abstinent cocaine abusers: a perfusion MRI and SPECT study. Psychiatry Res Neuroimaging 2000;99:63-74.

25. Weber DA, Franceschi D, Ivanovic M, et al. SPECT and planar imaging in crack abuse: iodine-123-iodoamphetamine uptake and localization. J Nucl Med 1993;34:899-907.

26. Tucker KA, Browndyke JN, Gottschalk PC, Cofrancesco AT, Kosten TR. Genderspecific vulnerability for rCBF abnormalities among cocaine abusers. Neuroreport 2004;15:797-801.

27. Chugani HT, Müller RA, Chugani DC. Funtional brain reorganization in children. Brain Dev 1996;18:347-356.

28. Holman BL, Mendelson J, Garada B, et al. Regional cerebral blood flow improves with treatment in chronic cocaine polydrug users. J Nucl Med 1993;34:723-727.

29. González JP, Vega TM, Soto PA, et al. Comportamiento de la perfusión cerebral com tomografia SPECT-99mTc etilencisteína dímero (ECD) em dependientes a alcohol y cocaíca duante abstinencia. Rev Esp Med Nucl 2002;21:410-416.

30. Gottschalck PC, Kosten TR. Cerebral perfusion defects in combined cocaine and alcohol dependence. Drug Alcohol Depend 2002;68:95-104.

31. Chugani HT. A critical period of brain development: studies of cerebral glucose utilization with PET. Preventive Medicine 1998;27:184-188.

32. Won HJ, Chang KH, Cheon JE, et al. Comparision of MR imaging with PET and ictal SPECT in 118 patients with intractable epilepsy. AJNR Am J Neuroradiol 1999;20:593-599.

33. Kim SK, Lee DS, Lee SK, et al. Diagnostic performance of [18F]-FDG-PET and ictal [99mTc]-HMPAO SPECT in occipital lobe epilepsy. Epilepsia 2001;42:1531-1540.

34. Buchert R, Obrocki J, Thomasius R, et al. Long-term effects of 'ecstasy' abuse on the human brain studied by FDG PET. Nucl Med Commun 2001;22:889-897. 